\title{
Does the Role a Pet Played before Disposition, and How the Pet is Lost Influence Pet Owner's Future Pet Adoption Decision?
}

\author{
Goitom Tesfom ${ }^{1} \&$ Nancy J. Birch ${ }^{2}$ \\ ${ }^{1}$ Department of Management, Eastern Washington University, USA \\ ${ }^{2}$ Department of Accounting and Information Sciences, Eastern Washington University, USA \\ Correspondence: Goitom Tesfom, Department of Management, Eastern Washington University, Cheney, \\ Washington, USA. E-mail: gtsegay@ewu.edu
}

\author{
Received: April 1, $2013 \quad$ Accepted: April 16, $2013 \quad$ Online Published: May 27, 2013 \\ doi:10.5539/ijms.v5n4p1 URL: http://dx.doi.org/10.5539/ijms.v5n4p1
}

\begin{abstract}
The purpose of the paper is to explore how the role a pet played before disposition and how the owner lost his/her pet affect the pet owner's next pet adoption decision. Results from Pearson chi-square tests of independence show no significant relationship between how the respondent viewed his/her pet before relationship ended and the length of time he/she waited before adopting another pet. However, a significant relationship was found between how the pet owner lost his/her pet and the length of time he/she waited before adopting another pet. Respondents who said they lost their pet voluntarily were more likely to wait longer before adopting another pet than those who said they lost their pet involuntarily. Moreover, the results confirm that respondents who viewed their pet as a child, before end of relationship, were more likely to hold funeral rituals than those who viewed their pet as a friend, a family or household member. Finally, those pet owners who lost their pets and decided to adopt another pet are likely to choose a pet of the same species but different breed. Implications to theory and practice are discussed.
\end{abstract}

Keywords: consumer behavior, social marketing, pet disposition, pet adoption decision, pet shelters

\section{Introduction}

The disposition stage of the pet consumption experience has not received a great deal of attention in the consumer behavior literature (Aylesworth, Chapman, and Dobscha 1999). Understanding the disposition decision stage of the pet consumption experience is important in two ways. First, each year six to eight million lost and unwanted pets end up at animal shelters across the U.S. and half of those animals must be euthanized (ASCPA 2012; Fournier and Geller 2004; Stephen and Brian 2009). Hence, understanding the disposition stage of the pet consumption experience may allow us to decrease the number of unwanted pets. Second, in the case of involuntary relationship termination (when the animal dies or is lost), examining the pet-human relationship before end of the relationship might be helpful in understanding its effect on future pet acquisition decisions (Aylesworth, Chapman, and Dobscha 1999; Hirschman 1994).

Hirschman (1994) discussed the various roles animals play in the lives of consumers. She explained that animals can serve as friends, family, objects and extensions of self. She provided a phenomenological evidence to support her views. This research extends Hirschman's work by exploring the influence of (a) the role the pet played in the owner's life (friend, family, objects and self) before disposition, and (b) the way the pet is lost (voluntarily or involuntarily), on the pet owner's future pet adoption decision. Quantitative empirical evidence on the pet-human relationship from the perspective of pet disposition is rather weak and often is based on descriptive case studies (Hirschman 1994; Stephens and Hill 1996). Thus, this research also fills part of the empirical gap. It complements the story-telling style research of Hirschman, Stephens and Hill, and others by providing empirical evidence. The better we understand this process, the more we can help consumers through it and increase the likelihood that they will readopt from pet shelters and pet rescue agencies.

According to the American Society for the Prevention of Cruelty to Animals (ASPCA), twenty six percent of dogs are purchased from breeders and 20-30 percent of cats and dogs are adopted from shelters and rescue agencies. Hence, our argument is consistent with the social marketing approach (Lefebvre 2011). It is based on the premise that nonprofit pet shelters and pet rescue agencies are facing competition from pet breeders. For nonprofit pet shelters and pet rescue agencies to win the competition, they need to understand the needs of their customers (Day 
1994; Gorke 2003; Kara Spillan, and DeShields Jr. 2004) and cater to them accordingly. Thus, to explore the role a pet played before relationship termination and the way a pet is lost on the future pet adoption decision of the pet owner, this study adopts consumer behavior from the marketing literature. In addition to the process by which individuals search for, select, purchase, and use, goods and services, consumer behavior also deals with how consumers dispose the goods and services. Hence the disposition stage is an important part of the consumer decision process.

\section{Literature Review}

Pet owners make several decisions in relation to their pets. Those decisions are often categorized as acquisition, consumption, and disposition (Aylesworth, Chapman, and Dobscha 1999; Hirschman 1994). Acquisition refers to the decision process consumers go through when making an adoption decision. The process consists of several activities including the adoption decision, breed choice decision and seller choice decision (Aylesworth, Chapman and Dobscha 1999). According to Aylesworth, Chapman, and Dobscha (1999) consumption decisions are the everyday interactions consumers have with their pets, the decisions made regarding feeding, exercise, day care etc. and decisions regarding the pet's health care. The disposition stage addresses the processes and the consequences when the animal-human relationship is terminated. Aylesworth, Chapman, and Dobscha (1999) explain that termination of the relationship with a pet can come voluntarily or involuntarily. It is voluntary when the owner gave it away or the animal runs away and involuntary, on both sides, when the animal dies or is lost.

Belk (1988) and others (e.g., Hirschman and LaBarbera 1990) have advocated closer examination of the enduring emotional ties that consumers cultivate with certain possessions, including pets. However, almost two decades later while marketers have begun to study pet adoption, pet food, pet accommodation, and the use of veterinary services (Brockman, Taylor, and Brockman 2008; Cheetham and McEachern 2013; Jyrinki and Leipamaa-Liskinen 2006; Gilly 2008; Hill, Gaines, and Wilson 2008; Leonard and Scammon 2007; Ridgway, Kukar-Kinney, Monroe, and Chamberlin 2008), little attention has been devoted to pet disposition by consumer researchers, (except Stephens and Hill 1996; Sanders 1990a ), and nothing has been written about factors that are related to pet disposition on the pet owners next adoption decision.

A pet may come to symbolize many things to each of us. Hirschman (1994) divides the roles animals play into two broad categories: animals as objects/products and animals as companions. In their roles as objects/products, animals can serve as ornaments (Working Party Council for Science and Society 1988), status symbols (Beck and Katcher 1983; Savishinsky 1986; Working Party Council for Science and Society 1988), as avocation (Tuan 1984; Working Party Council for Science and Society 1988), and as equipment (Cass 1981; Corson and Corson 1981; Fogle 1981; Working Party Council for Science and Society 1988). Moreover, animals as companions can serve as friends (Hirschman 1994; Cass 1981; Corson and Corson 1981; Feldmann 1979; Levinson 1969; McCulloch 1983; Savishinsky 1986; Working Party Council for Science and Society 1988), an extension of self (Beck and Katcher 1983; Belk 1988; Feldmann1979; Savishinsky1986), a brother/sister (Beck and Katcher 1983; Hirschman 1994; Voith 1983), and/or a child (Feldmann 1979; Hirschman 1994; Beck and Katcher 1983; Sanders 1990a; Serpell 1986; Wallendorf and Arnould 1991; Working Party Council for Science and Society1988). Although animals do serve consumers in utilitarian, aesthetic, or facilitative roles, many, perhaps the majority, act as companions to their human owners (Hirschman 1994).

Every pet owner potentially faces the loss of his or her companion animal. Losing a pet, whether to illness, accidental death, or old age, often can be as difficult as losing a friend or family member (Stephens and Hill 1996). Many people share a special bond with their companion animal and mourn the loss greatly (Belk 1988; Hirschman 1994; Stephens and Hill 1996). How an individual responds to the death of an animal companion is a function of a myriad of factors, including the degree of attachment (Gage and Holcomb 1991; Harris 1983; Sanders 1995). Many people think about adopting a new pet immediately after the loss of their pet. This is often as a response to their grief and sense of loss or a way to try to fill the void the loss of their pet has created in their lives. However, some people may find it difficult to have another pet (Stephens and Hill 1996). Hence, this study intends to explore how the role the pet played before relationship termination and the way the owner lost his or her pet and its effect on the pet owner's next adoption decision. Accordingly the next section discuses the four major roles pets play in the life of humans before end of relationship, the way the pet is lost, and the consumer's decisions with regard to pet goodbye rituals and pet species and breeds choices.

\subsection{Role of a Pet before Relationship Termination}

In this research, the roles pets play before relationship termination refer to pet as family, pet as friend, pet as self and pet as property. 


\subsubsection{Pet as Family}

Many people treat their birds, cats, or other animals as members of their family (Hirschman 1994). According to Stephen and Hill (1996, p.197) animal companions often were referred to as "son," "daughter," or "baby," and owners referred to themselves as "mommy" or "daddy". The Merriam Webster online dictionary defines family as, "a group of individuals living under one roof; a group of persons of common ancestry; or a group of things related by common characteristics". People who view their pets as part of their families, brother/sister, or a child before relationship termination are probably less likely to adopt another pet immediately. This is mainly because the pet owners may think that a child or a brother or a sister is not replaceable (Stephens and Hill 1996). Furthermore, this may be especially true when children are present in the household as it sends a wrong message to a child that says when something is lost all you have to do is get another one. It also devalues the significance of the pet that just died. According to Stephens and Hill (1996), a child's parents were unwilling to have another animal because they did not wish to experience another loss. Moreover, as evidence to the previous argument, Stephens and Hill (1996, p. 201) documented the following conversation with a pet owner who lost his pet: "I originally thought that I did not want another pet to replace him. I saw Triever as a part of the family, and you cannot just replace a family member". Often pet owners who lost their pets conduct burial rituals. However, it is likely that the greater a pet owner considers a pet as a family member, the more likely the owner will conduct a burial or memorial rituals.

\subsubsection{Pet as Friend}

Many people's relationships with their pets fall into this category (Hirschman 1994). The Merriam-Webster online dictionary defines a friend as, "one attached to another by affection or esteem, or a favored companion". As friends animals may be especially valuable and comforting (Hirschman 1994). According to Hirschman, consumers and their animal companions commonly develop a mutually evolving relationship that defines their lives together. As a friend the animal is "perceived and treated as a subject, as a personality in its own right" (Working Party Council for Science and Society 1988). However, with the loss of a pet, people who viewed their pets as friends are more likely to have fewer problems in replacing their lost pet than those who view their pets as a family which signifies an assumed blood ties or ancestry.

\subsubsection{Pet as Self}

Previous research claimed that consumer's possessions reflect consumer's self (Belk 1988; Feldmann 1979; Hirschman 1994; Jyrinki 2012; Sanders 1990a; Savishinsky 1986). Feldmann (1979) was one of the first to observe that pets can be extensions of how pet owners see themselves. Building on Feldmann's work, Savishinsky (1986) stated that human's choice of a pet is itself a definition of self and that the pet could be compared to a hair style or clothing. Also, Belk (1988) argues that animals may act as extensions of the consumer, and in this role the animal's traits, behaviors, and appearance are seen as being those of its owner. Often the owner projects his or her own personality onto the animal and absorbs the animal's nature onto himself or herself. Moreover, according to Belk (1988) and latter Hirschman (1994), owners project their self-identity onto their pets in which their pets are seen as extensions of ego and act as a form of self-definition. Consistent with the previous argument additional dramatic evidence is found in the diminished sense of self when possessions are unintentionally lost or stolen (Belk 1988). Hence, for pet owners who considered their pets as self before relationship termination, it is likely that replacing a lost pet may be considered as similar to replacing part of self, which, in reality is often not true.

\subsubsection{Pet as Property}

According to Hirschman (1994) and later Francione (2000), pets in their roles as property (objects/products), are reduced from their status as consumers' companions to objects in the consumers' environment. Object pets may serve as ornaments (e.g., exotic fish or birds acquired for their beauty), as status symbols (e.g., thoroughbred horses), or as equipment (hunting pets, carriage horses). Pet owners who viewed their pet as property (instruments or objects) may abandon the pet, and are less likely to suffer greatly from the loss of a pet (Belk 1988). In this more utilitarian view, owners merely regret the loss of valued possessions because of the benefits the latter provided, rather than from any feelings self-derived from or mingled with these objects. Moreover, after relationship termination the pet owners are more likely to replace the pet they lost in a shorter period of time than those who viewed their pet as a family.

\subsubsection{How the Pet Is Lost}

Aylesworth, Chapman, and Dobscha (1999) classify termination of the pet-human relationship as voluntary and involuntary. Voluntary pet-human relationship termination comes when an animal runs away or the human partner either gives the animal up to a shelter or other care-giver, or abandons the animal without any care available. Involuntarily pet-human relationship termination, on both sides, may include when the animal dies or is lost. The 
most extreme form of involuntary relationship termination may be euthanasia, which is the act of ending the life of a pet that is suffering from an incurable disease or condition in a humane manner. Euthanasia can be done for many reasons, including when a pet is terminally ill and will deteriorate, has severe injuries from which it will not recover, has irresolvable behavior problems, or has age related problems which cannot be alleviated. Several researchers (Gerwolls and Labbot 1994; Gosse and Barnes 1994; Stephens and Hill 1996) indicated that the grief associated with a loss of a pet is similar to that associated with human death. Hence, to request euthanasia of a pet may be one of the most difficult decisions a pet owner makes. After the incidence of involuntary pet-human relationship termination, euthanasia in particular, it is more likely that the pet owner will be unwilling to have another animal, usually because he/she does not wish to experience another loss (Stephens and Hill 1996).

\subsubsection{Same or Different Pet}

After the pet-human relationship is terminated, voluntarily or involuntarily, the pet owner may want to adopt another pet. In the process of such a decision, often, the first question that comes to the adopter's mind is whether to adopt the same or different pet species and breed. The literature provides mixed results. One group of authors argues that if the pet owner enjoyed the companionship of his/her previous pet, there is no reason he/she should not enjoy similar companionship with the same pet species and breed (Aylesworth, Chapman, and Dobscha 1999; Belk 1988). Aylesworth, Chapman, and Dobscha (1999) suggest that a close relationship with previous pet may result in the consumer choosing another pet of the same species and breed. The previous argument is based on the premise that adopters consider the temperament, care requirements, and fit to their lifestyle when they choose a pet. Hence, if they were happy with their previous pet, it is more likely that they will be happy with a pet of similar species and breeds. However, a second group of authors see the issue differently. They argue that all pets are individuals and the same species and breed does not mean it will have the same personality. Hence, they advise that adopters to accept and love the new pet for the individual that it is, and stop comparing the new pet to the memory of the old one. If they do, the new pet will always come up short and in that case the pet owners would probably be disappointed. The authors of this paper argue that after the relationship with the previous pet is terminated, the factors that made the pet owner choose a specific species and breed may still be in place. In support of the previous argument evidence from Hirschman's (1994) interview suggests that U.S. males may prefer dogs to cats because of dogs' greater responsiveness to commands. Hence, for the same reason mentioned before, it is more likely that a male who lost a dog and decided to adopt another pet is going to adopt the same species, dog than a cat. Similarly, if the male owned a Hound breed dog before relationship termination and was happy about it, when he/she decides to readopt, he/she may choose a Hound breed dog. The forgoing discussion leads us to the four hypotheses described in the next sub-section.

\subsubsection{Hypotheses}

The forgoing discussion leads to the following hypotheses:

1) The role a pet played before relationship termination and future pet adoption decision are related. The stronger the pet-human bond before relationship termination the greater the time before a new pet is obtained.

2) The way the pet owner lost his or her pet and the owner's next pet adoption decision are related. That is, pet owners who involuntarily lost their pet are more likely to wait longer to acquire a new pet than those who lost their pet voluntarily. There may be some interactions as well. For example, pet owners who had a strong bond with their pet and lost their pet involuntarily are more likely to wait longer for a new pet than those who did not have a strong bond.

3) The role a pet played before relationship termination and pet owner's arrangement of goodbye funeral rituals are related. The stronger the pet-human bond before relationship termination the more likely the pet owner is going to arrange burial or memorial rituals for his/her pet.

4) Those pet owners who lost their pet and decided to adopt another pet are more likely to choose a pet of the same species and breed.

\section{Method}

\subsection{Sample}

This research follows a positivistic approach and relies heavily on quantitative data (Wacquant, 1992; Gartrell and Gartrell 1996). Hence, the research conducts systematic empirical investigation of quantitative properties and phenomena and their relationships. To test the hypotheses, the study used a survey of pet owners who lost their pets and are employed at two higher education institutions in the state of Washington, United States. The two higher education institutions represent Eastern and Western regions of the state of Washington. The list of respondents who lost their pets was compiled from a previous survey that focused on pet adoption and administered on the pet 
owners. The survey targeted all pet owners who lost their pets and employed at the two higher education institutions. An email with a link to the survey was sent to 1,042 past and current pet owners who lost their pets. If they had multiple previous lost pets, respondents were instructed to just respond in the context of the most recently lost pet. After accounting for bounce-back messages and technical errors, the final number of potential respondents was 879 . The survey response was 184 for a response rate of $20.9 \%$. The survey was conducted online between December 23, 2011, and January 29, 2012. A follow up reminder was used to increase the response rate and to minimize non-response bias (Hoonakker and Carayon 2009).

\subsection{Questionnaire Design}

The online questionnaire consisted of 16 questions, with several sections, that include the type of the human-pet relationship prior to relationship termination, the way the pet is lost, the future pet adoption decision, and owner's arrangement of pet goodbye (funeral, memorial etc.) rituals. The variables are adopted from Aylesworth, Chapman, and Dobscha (1999) animal consumption lifecycle framework. The questionnaire ended with six demographic questions. Included with the demographic questions were how many pets are in the household during the relationship termination and the length of time the pet owner owned the pet(s). The questionnaire was pretested on 20 pet owners who lost their pets and their feedback was incorporated into the final questionnaire to minimize question wording ambiguity and response bias (Cooper and Schindler 2011).

\subsection{Measurement}

The level of agreement of the respondents to statements related to the role the pet played before pet-human relationship termination, the type of pet-human relationship termination, and the pet owner's next pet adoption decision were rated using a 7 point likert-type scale ranging from "Strongly disagree" (1) to "strongly agree" (7).

\subsubsection{Validity and Reliability of Measurement}

Due to the lack of existing validated scales to measure the variables, the authors pre-tested the questionnaire on a sample of individuals who were part of the target population and the input was used to modify the questionnaire. The questions were deemed to possess face and content validity by the authors (Zikmund, Babin, Carr, and Griffin 2010). Face validity of the measures was established by the agreement between the authors in that the questions and scales logically reflected the concepts being measured. Further, the authors determined the measures included in the questionnaire covered the domain of interest and thus met content validity.

\subsection{Data Analysis Methods}

Frequency tables are used to summarize the results. Pearson chi-square tests of independence are used to test the hypotheses and to determine if significant relationships existed between variables of interest. For some chi-square tests adjacent categories of the contingency table had to be combined to insure test assumption validity.

\subsection{Respondent Characteristics}

A total of 184 respondents completed the online survey; 57 (33\%) were males and 115 (67\%) were females (totals may not add to 184 due to item non-response). Percent reflects valid percent, that is, the percentage of none missing data (Leech, Barrett, and Morgan 2008). Tables 1 through 9 summarize other respondent characteristics.

Table 1. What was your age when your relationship with your pet ended?

\begin{tabular}{lll}
\hline Age & Frequency & Valid* Percent \\
\hline Less than 20 years old & 13 & 7 \\
20-29 years old & 17 & 10 \\
$30-39$ years old & 32 & 18 \\
$40-49$ years old & 48 & 27 \\
$50-59$ years old & 49 & 28 \\
$60-69$ years old & 16 & 9 \\
70 or above years old & 1 & 1 \\
\hline Total responses & 176 & 100 \\
\hline
\end{tabular}

${ }^{*}$ Valid percent excludes missing values. Percent may not equal 100 due to rounding. 
Table 2. What was your marital status when your relationship with your pet ended?

\begin{tabular}{lll}
\hline Marital status & Frequency & Valid $^{*}$ Percent \\
\hline Young single (under age 40) & 33 & 19 \\
Older single (age 40 or older) & 27 & 15 \\
Newly married couple with no children & 6 & 3 \\
Married with children in the home & 29 & 16 \\
Married with children, but the children have left home & 28 & 16 \\
Married no children & 26 & 15 \\
Single parent & 10 & 6 \\
Other & 17 & 10 \\
\hline Total responses & 176 & 100 \\
\hline
\end{tabular}

${ }^{*}$ Valid percent excludes missing values. Percent may not equal 100 due to rounding.

Table 3. What was your annual gross household income when your relationship with your pet ended?

\begin{tabular}{lll}
\hline Annual gross household income & Frequency & Valid $^{*}$ Percent \\
\hline Less than $\$ 19,999$ & 16 & 10 \\
$\$ 20,000-39,999$ & 23 & 14 \\
$\$ 40,000-59,999$ & 30 & 19 \\
$\$ 60,000-79,999$ & 37 & 23 \\
$\$ 80,000-99,999$ & 20 & 13 \\
$\$ 100,000-119,999$ & 22 & 14 \\
More than $\$ 120,000$ & 12 & 8 \\
\hline Total responses & 160 & 100 \\
\hline
\end{tabular}

${ }^{*}$ Valid percent excludes missing values. Percent may not equal 100 due to rounding.

Table 4. What was your highest level of education when your relationship with your pet was ended?

\begin{tabular}{lll}
\hline Level of education & Frequency & Valid* Percent \\
\hline Graduate degree (Master's MD, DVM, PhD, etc. & 87 & 50 \\
Bachelor's degree or equivalent & 35 & 20 \\
Associate degree or equivalent & 24 & 14 \\
Trade qualification (less than two years college level training) & 7 & 4 \\
High school diploma or equivalent & 12 & 7 \\
Less than high school qualification & 6 & 3 \\
Other & 4 & 2 \\
\hline Total response & 175 & 100 \\
\hline
\end{tabular}

${ }^{*}$ Valid percent excludes missing values. Percent may not equal 100 due to rounding.

Table 5. How many pets did you have in the household when your relationship with your previous pet ended?

\begin{tabular}{lll}
\hline Number of pets & Frequency & Valid*Percent \\
\hline One & 76 & 43 \\
Two & 66 & 38 \\
Three & 23 & 13 \\
Four & 8 & 5 \\
More than four & 3 & 2 \\
\hline Total responses & 176 & 100 \\
\hline
\end{tabular}

${ }^{*}$ Valid percent excludes missing values. Percent may not equal 100 due to rounding. 
Table 6. For how long had you had your pet?

\begin{tabular}{lll}
\hline Number of years & Frequency & Valid* Percent \\
\hline Less than a year & 14 & 10 \\
A year but less than two years & 13 & 9 \\
Two years but less than three years & 24 & 17 \\
Three years but less than four years & 9 & 6 \\
Four years but less than five years & 14 & 10 \\
Five years or more & 70 & 49 \\
\hline Total responses & 144 & 100 \\
\hline
\end{tabular}

Table 7. From where did you adopt or acquire your most recent pet?

\begin{tabular}{lll}
\hline Number of years & Frequency & Valid* Percent \\
\hline Animal shelter & 29 & 28 \\
Rescue agency & 18 & 17 \\
Pet owner looking to give away pet & 16 & 15 \\
Pet store & 3 & 3 \\
Pet breeder & 20 & 19 \\
Other & 19 & 18 \\
\hline Total responses & 105 & 100 \\
\hline
\end{tabular}

${ }^{*}$ Valid percent excludes missing values. Percent may not equal 100 due to rounding.

Table 8. Approximately how long ago did you lose your pet?

\begin{tabular}{lll}
\hline Time since lost pet & Frequency & Valid* Percent \\
\hline Less than a year ago & 27 & 15 \\
A year ago but less than two years ago & 21 & 12 \\
Two years ago but less than three years ago & 31 & 18 \\
Three years ago but less than four years ago & 11 & 6 \\
Four years ago but less than five years ago & 12 & 7 \\
Five years or more ago & 74 & 42 \\
\hline Total responses & 176 & 100 \\
\hline
\end{tabular}

"Valid percent excludes missing values. Percent may not equal 100 due to rounding.

Table 9. What type of pet did you have when your relationship ended with that pet?

\begin{tabular}{lll}
\hline Answer & Frequency & Valid $^{*}$ Percent \\
\hline Dog & 94 & 54 \\
Cat & 73 & 42 \\
Other & 8 & 5 \\
\hline Total responses & 175 & 100 \\
\hline
\end{tabular}

*Valid percent excludes missing values. Percent may not equal 100 due to rounding.

A typical (most likely) respondent appears to be female between 50 to 59 years of age $(49,28 \%$ ), with an annual gross household income between $\$ 60,000$ and $\$ 80,000$ (37, 23\%), and has a graduate degree $(87,50 \%)$. Respondents were almost equally likely to be single (34\%) or married (32\%).

Most respondents (76, 43\%) were one pet household, followed by two pet households (66, 38\%). Seventy (49\%) respondents had their pet for at least five years and $24(17 \%)$ reported having their pet for two but less than three years. Ninety-four (54\%) respondents reported losing a dog; seventy-three (42\%) reported losing a cat. Seventy-four (42\%) respondents reported they lost their pet five or more years ago and twenty-seven (15\%) lost 
their pet less than a year ago. Thirty-seven (35\%) respondents adopted or acquired their most recent pet from an animal shelter or animal rescue agency and twenty $(19 \%)$ reported they adopted their new pet from a breeder. In summary, a typical (most likely) respondent reported losing a dog, five or more years ago, were one pet households, and adopted a new pet from an animal shelter.

\section{Discussion}

\subsection{Role of a Pet before Relationship Ended}

Respondents were asked how they viewed their pet before the relationship with the pet ended. Table 10 summarizes the results. A majority of the respondents $(96,53 \%)$ viewed their pet as a friend. Also $48(26 \%)$ of the respondents viewed their pet as a child. Classified under other were responses such as "family member" (10 out of 32) or "companion animal" (10 out of 32). Single responses under the other category included: "victim needing help," "object of worship," "a great pet," and "as a pet, part infant, part chore".

Table 10. Before your relationship ended, how did you primarily view your pet?

\begin{tabular}{lll}
\hline How pet viewed & Frequency & Valid* Percent \\
\hline As a friend & 96 & 53 \\
As self & 0 & 0 \\
As a child & 48 & 26 \\
As a brother or sister & 5 & 3 \\
As an object & 0 & 0 \\
As a helper & 1 & 1 \\
Other & 32 & 18 \\
\hline Total responses & 182 & 100 \\
\hline${ }^{*}$ Valid percent excludes missing values. Percent may not equal 100 due to rounding. \\
Sixty percent (Note 1) (111) of the respondents reported they adopted another pet after losing a pet. Further, they \\
were asked how long they waited before adopting or acquiring another pet. Table 11 summarizes the results. \\
Sixty-three percent (67) of those who adopted another pet did so within a year of the loss of their pet.
\end{tabular}

Table 11. After your relationship with your previous pet ended, for how long did you wait before you adopted another pet?

\begin{tabular}{lll}
\hline Source of adoption & Frequency & Valid $^{*}$ Percent \\
\hline Less than a year & 67 & 63 \\
A year but less than two years & 21 & 20 \\
Two years but less than three years & 4 & 4 \\
Three years but less than four years & 6 & 6 \\
Four years but less than five years & 3 & 3 \\
Five years or more & 5 & 5 \\
\hline Total responses & 105 & 100 \\
\hline
\end{tabular}

"Valid percent excludes missing values. Percent may not equal 100 due to rounding.

For research hypothesis 1 , no significant relationship was detected between how the respondent viewed his/her pet and the length of time he/she waited before adopting another pet (Pearson Chi-Square $=1.045, \mathrm{DF}=2, \mathrm{P}-$ Value $=$ 0.593). Thus, research hypothesis 1 is not supported. This may be because $63 \%$ of all respondents adopted a pet within a year of losing their last pet and $83 \%$ adopted another pet within 2 years.

\subsection{How the Pet Is Lost}

Respondents were asked how their relationship with their pet ended. Table 12 shows the summary results. One hundred sixty-six $(90 \%)$ of the respondents reported that their pet either died or was euthanized. Research hypothesis 2, the way the pet owner lost his or her pet and the owner's next pet adoption decision are related, is not supported. However a significant relationship was found between how the pet owner lost his/her pet and the length of time before adopting another pet (Pearson Chi-Square $=11.404, \mathrm{DF}=4$, P-Value $=0.022$ ). Respondents who 
said they lost their pet voluntarily (gave it up for various reasons) were more likely to wait longer (more than 2 years) than those who lost their pet involuntarily (died or ran away). A logical explanation could be that pet owners felt they had compelling reasons (rental or housing restrictions, pet behavior issues, cost, etc.) that led them to voluntarily give up their pet. Whereas, pet owners who involuntarily lost their pet might be anxious to adopt soon in order to regain that human-animal bond. No significant difference in time to adopt another pet and whether the pet died or was euthanized was found (Pearson Chi-Square $=0.00, \mathrm{DF}=2, \mathrm{P}$-Value $=1.00$ ).

Table 12. My relationship with my pet was ended because

\begin{tabular}{lll}
\hline Primary reason & Frequency & Valid Percent \\
\hline Gave it up to a shelter & 3 & 2 \\
Gave it up to a caregiver & 3 & 2 \\
Gave it up to a family member & 4 & 2 \\
Abandoned or ran away & 4 & 2 \\
Pet died & 70 & 38 \\
Pet was euthanized & 96 & 52 \\
Other & 3 & 6 \\
\hline Total responses & 183 & 100.0
\end{tabular}

${ }^{*}$ Valid percent excludes missing values. Percent may not equal 100 due to rounding.

Relating to research hypothesis 2, no interactions were detected between the pet owner's bond with their pet, time before adopting another pet, and whether the relationship ended voluntarily or not (Pearson Chi-Square $=0.297$, $\mathrm{DF}=2, \mathrm{P}$-Value $=0.0 .862$; Pearson Chi-Square $=0.173, \mathrm{DF}=2, \mathrm{P}-$ Value $=0.917$ ). This could be because most respondents reported having a strong bond with their pet. Specifically, 96 (53\%) of respondents viewed their pet as a friend. Forty-eight (26\%) viewed their pet as a child, and $32(18 \%)$ viewed their pet as other; a family member or a companion. In addition, 96 (52\%) of respondents reported that their pet was euthanized.

\subsection{Goodbye and Funeral Rituals}

Respondents were asked if they conducted goodbye rituals (funeral, memorial, etc.) after the loss of their pet. Table 13 presents the results. Eighty-two (47\%) respondents reported conducting goodbye rituals (funeral, memorial, etc.) after losing their pet; $80(45 \%)$ said they did not have goodbye rituals. Other (11, 6\%) responses included respondents who "cremated and saved remains", "donated money to charity", and "cried a lot".

Table 13. After your relationship with your pet ended did you conduct goodbye rituals (funeral, memorial, etc.)?

\begin{tabular}{lll}
\hline Choices & Frequency & Valid Percent \\
\hline Yes & 82 & 47 \\
No & 80 & 45 \\
I am planning for it. & 3 & 2 \\
Other & 11 & 6 \\
\hline Total responses & 176 & 100 \\
\hline
\end{tabular}

${ }^{*}$ Valid percent excludes missing values. Percent may not equal 100 due to rounding.

Research hypothesis 3 is supported. A significant relationship was found between the role the pet played prior to relationship termination and the pet owner's arrangement of funeral rituals (Pearson Chi-Square $=8.152, \mathrm{DF}=3$, P-Value $=0.043$ ). On closer inspection, respondents who viewed their pet as a child were more likely to hold funeral rituals $(65 \%)$ than not $(35 \%)$.

\subsection{Same or Different Pet}

Respondents who reported they adopted another pet after losing their pet were asked what type of pet they adopted. Table 14 gives the summary results. Ninety-six (90.5\%) of the respondents reported that they adopted both same 
species and breed, or the same species but different breed pet. For research hypothesis 4 , those pet owners who lost their pet and decided to adopt another pet are less likely to choose a pet of the same species and same breed. Of those respondents who adopted another pet, 35 (33\%) chose to adopt the same species and breed of pet as before, whereas sixty one $(57.5 \%)$ respondents reported that they chose to adopt the same species but a different breed. This difference was statistically significant $(\mathrm{Z}=3.59, \mathrm{P}-$ Value $=0.001)$.

Table 14. If you adopted another pet after losing a pet, what type of pet did you adopt?

\begin{tabular}{lll}
\hline Choices & Frequency & Valid $^{*}$ Percent \\
\hline Same species and breed & 35 & 33.0 \\
Same species but different breed & 61 & 57.5 \\
Different species & 9 & 8.5 \\
\hline Total responses & 106 & 100 \\
\hline *Valid percent excludes missing values. Percent may not equal 100 due to rounding.
\end{tabular}

The previous result is the opposite of what was hypothesized. This may have occurred because 29 (28\%) respondents reported that they adopted their pet from an animal shelter, or the pet was rescued $(18,17 \%)$ or the pet was acquired from someone looking to give away a pet (16,15\%). Hence, due to the way the pet owners acquired their new pet, they may have had limited or no input on breed choice decision. Whereas, for those twenty (19\%) who adopted their pet from a breeder, they would be likely to determine the species and breed they wanted to adopt.

\section{Conclusion}

The purpose of this study is to understand the disposition stage of the pet consumption experience and how factors such as the role the pet played before relationship termination, and the way the owner lost his or her pet affect the pet owner's next pet adoption decision. The survey results suggest that there is no significant relationship between the role the pet played before relationship termination and the owner's future pet adoption decision. Accordingly hypothesis 1 "the stronger the pet-human bond before relationship termination the longer the time before a new pet is obtained" is not supported. The finding is inconsistent with the suggestion by Aylesworth, Chapman, and Dobscha (1999, p.386) that "the nature of the relationship between the human and the animal that develops during the consumption stage is likely to affect future acquisition decisions". Although the study did not support hypothesis 2 , that is, pet owners who involuntarily lost their pet are more likely to wait longer to acquire a new pet than those who lost their pet voluntarily, the results suggests that pet owners who lost their pets involuntarily are faster to adopt another pet than those who lost their pet voluntarily. Moreover the study confirms that the stronger the pet-human bond before relationship termination the more likely the pet owner is going to arrange burial or memorial rituals for his/her pet. Hence, hypothesis 3 is supported. The latter is in line with Stephens and Hill (1996) finding that the death of animal companion may result in grief consistent with death of a family member, thus some relief may be provided through goodbye rituals. Finally those pet owners who lost their pet and decided to adopt another pet are more likely to choose a pet of the same species but different breed. The research findings have significant contribution to theory and practice.

\section{Managerial Implications}

Understanding how the role the pet played before relationship termination and the way the owner lost his or her pet affects the pet owner's next adoption decision is a useful tool to pet shelters and rescue agencies in their endeavor to match the right pet to the right adopter. Very limited previous studies, Stephens and Hill 1996, indicate that unwillingness to adopt replacement pet by pet owners who lost their pets could be associated with fear of not wanting to experience another loss or not wanting to send $\mathrm{s}$ message to children that a family member is replaceable. However our findings indicate that there is no significant relationship between the role a pet played before relationship termination and the length of time before the pet is replaced. The fact that sixty-three percent (67) of those who adopted another pet did so within a year of the loss of their pet, it could be inferred that acquiring a replacement pet within a short period of time after the loss of a pet may have been considered as part of the healing process of the pet owner who lost his/her pet. In their research based on interpretation of textual data, Stephens and Hill (1996) argued that the unexpected death of animal companion resulted in a grief consistent with a family member and requires the braved owner to get past the stage of fearing a new relationship and obtain a new pet. However it can also be argued that a family who lost a child and was then blessed with another child is more 
likely to recover quickly from the grief than a family that did not get another child. Hence, the authors of this research argue that replacement pets could help the pet owners who lost their pets to at least shorten the grief period. Consequently pet adoption services could include acquiring a new pet after a loss of a pet as one element of counseling services that target people who lost their pets. Ultimately such service will help to increase the number of pets adopted. Counseling agencies can come in contact with pet owners who lost their pets involuntarily in several ways. First, some of the pet owners might have already adopted their lost pet from the same agencies and after the involuntary loss of the pet; it is natural for the grieving pet owners to let the agencies know about the loss of their pet. Second, nowadays pet euthanasia is done by veterinarians. Hence, the counseling agencies could work in cooperation with the veterinarians engaged in the business of euthanizing pets. Lastly, blog pages where pet owners who lost their pets express their grief could also be a source of wealth of information to the counseling agencies.

However such counseling services should focus on pet owners who lost their pets involuntarily. As our finding suggests pet owners who lost their pets voluntarily tend to take more time to adopt a replacement pet than those who lost their pet voluntarily. Pet owners lose their pets voluntarily mainly because of living and financial arrangements changed drastically, the owner experienced severe health problems, people moved across borders and difference in legal systems made it impossible for them to take their pets with them, owners might have developed allergy to their pets or the pet might have medical or behavioral problems that the owner is not ready to address. Because those pet owners who lost their pets voluntarily need more time to sort out their problems, advising them to adopt another pet could lead to another voluntary loss of a pet. It is better to let them do so when they feel they are ready.

Our finding that states pet owners who lost their pets are more likely to adopt another pet of similar species but different breed is also useful to pet shelters and rescue agencies because it could help them to match the right pet species to the right pet adopter. Pet shelters and rescue agencies could easily determine the species that pet owners who lost their pets might prefer to adopt just by asking the pet owners about the species of their lost pets.

\section{Implications to Theory}

The disposition stage of the human pet relationship has not received a great deal of attention in the consumer behavior literature. In her seminal work Hirschman (1994) discussed the various roles companion animals play in the lives of consumers. Our research extends Hirschman work by exploring the influence of the role a pet played before disposition and the way the pet is lost on the pet owner's future pet adoption decision. Quantitative empirical evidence on the pet-human relationship from the perspective of pet disposition is rather weak and often based on descriptive case studies (Hirschman 1994; Stephens and Hill 1996). Thus, this research fills part of the empirical gap. It complements the story-telling style research of Hirschman and Stephens and Hill and others by providing empirical evidence. While the positivist approach does not explain all aspects of the self, researchers in the field have long advocated for the need to support the interpretative nature of the current research with quantitative studies. According to Aylesworth, Chapman, and Dobscha (1999, P. 385) "As in a choir, with each voice adding to the beauty of the whole, each method used to study pet consumption will only serve to enrich our understanding". The better we understand this process, the more we can help consumers through it and ultimately increase the likelihood that they will decide to adopt again. The study also draws attention to the fact that the household decision-making literature would benefit from dog adoption research that involves less mundane, more emotional purchases than household goods (Gilly, 2008).

\section{Research Implications}

While the present research provides important insights on how factors such as the role a pet played before relationship termination and the way the owner lost his/her pet affect the pet owners next pet adoption decision, the research has a couple of limitations. First the survey was conducted with employees of two higher education institutions. Thus, the results need to be tested on a diverse population of pet owners. Second, in the sample women were more highly represented than men. Although such differences have been observed in earlier similar studies, further effort must be made to determine if the conclusions drawn from this study apply to other groups as well.

\section{Directions for Future Research}

Based on this study's findings, at least one factor may warrant further investigation. Although previous studies indicate that unwillingness to adopt a replacement pet by pet owners who lost their pet could be usually associated with fear of not experiencing another loss or not to send to children that a family member is replaceable (Stephens and Hill 1996), our findings indicate that there is no significant relationship between the role a pet played before relationship termination and the length of time before the pet is replaced. Moreover sixty-three percent (67) of those who adopted another pet did so within a year of the loss of their pet. Hence, further research could investigate 
the discrepancy between the two findings and its implications to the theory of consumer behavior. The future of the relationship between pet owners and their companions is bright and the authors of this paper encourage others to delve into these topics further. Since research on pet disposition in the framework of consumer behavior is limited, the authors also hope that the findings in this research will serve as a potential new theoretical idea to encourage future research in the area.

\section{References}

American Society for the Prevention of Cruelty to Animals (ASPCA). (2012). Facts about U.S. Animal Shelters. Retrieved October 14, 2012, from http://www.aspca.org

Aylesworth, B., Chapman, K., \& Dobscha, S. (1999). Animal companions and marketing: Dogs are more than just a cell in the BCG matrix. Advances in Consumer Research, 26, 385-391.

Beck, A., \& Katcher, A. (Eds.). (1983). Between pets and people. New York: G.P. Putnam's Sons.

Belk, R. W. (1988). Possessions and the extended self. Journal of Consumer Research, 15(2), 139-168. http://dx.doi.org/10.1086/209154

Brockman, B. K., Taylor, V. A., \& Brockman, C. M. (2008). The price of unconditional love: Consumer decision making for high-dollar veterinary care. Journal of Business Research, 61(5), 397-405. http://dx.doi.org/10.1016/j.jbusres.2006.09.033

Cass, J. (1981). Pet Facilitated Therapy in Human Health Care. In B. Fogle (Ed.), Interrelations between People and Pets (pp.124-145). Springfield, IL: Charless C.Thomas.

Cheetham, F., \& McEachern, M. G. (2013). Extending Holt's consuming typology to encompass subject-subject relations in consumption: Lessons from pet ownership. Consumption Markets \& Culture, 16(1), 91-115. http://dx.doi.org/10.1080/10253866.2011.652826

Cooper, D. R., \& Schindler, P. S. (2011). Business Research Methods (11th ed.). New York: McGraw-Hill/Irwin.

Corson, S. A., \& Corson, E. O. (1981). Companion Animals as Bonding Catalysts in Geriatric Institutions. In B. Fogle (Ed.), Interrelations between People and Pets (pp. 146-174). Springfield, IL: Charles C Thomas.

Day, G. S. (1994). The capabilities of market driven organizations. Journal of Marketing, 8(4), 37-52. http://dx.doi.org/10.2307/1251915

Feldmann, B. M. (1979). Why people own pets. In R. D. Allen \& W. H. Westbrook (Eds.), The Handbook of Animal Welfare. New York: Garland STPM.

Fogle, B. (1981). Attachment-euthanasia-grieving. In B. Fogle (Ed.), Interrelations between people and pets (pp. 331-342). Springfield, IL: Charles C. Thomas.

Fournier, A. K., \& Geller, S. E. (2004). Behavior Analysis of Companion-Animal Over population: A Conceptualization of the Problem and Suggestions for Intervention. Behavior and Social Issues, 13, 51-68.

Fracione, G. (2000). Introduction to Animal Rights: Your Child or the Dog? Philadelphia: Temple University Press.

Gage, M., \& Holcomb, R. (1991). Stressfulness of death of the family pet. Family Relations, 103-105. http://dx.doi.org/10.2307/585666

Gartrell, D. C., \& Gartrell, J. W. (1996). Positivism in Sociological Practice: 1967-1990. Canadian Review of Sociology and Anthropology, 33, 143-158. http://dx.doi.org/10.1111/j.1755-618X.1996.tb00192.x

Gerwolls, M. K., \& Labott, S. M. (1994). Adjustment to the death of a companion animal. Anthrozoös, 7, 172-187. http://dx.doi.org/10.2752/089279394787001826

Gilly, M. C. (2008). The Price of Peace in the Household: A Commentary on the Price of Unconditional Love: Consumer Decisions Concerning High-Dollar Veterinary Care. Journal of Business Research, 61(5), 406-407. http://dx.doi.org/10.1016/j.jbusres.2007.04.012

Goerke, J. (2003). Taking the quantum leap: Non profits are now in business, An Australian Perspective. Journal of Non Profit and Voluntary Sector Marketing, 8(4), 317-327. http://dx.doi.org/10.1002/nvsm.222

Gosse, G. H., \& Barnes, M. J. (1994). Human grief resulting from the death of a pet. Anthrozoös, 7, 103-112. http://dx.doi.org/10.2752/089279394787001970

Harris, J. (1983). A study of client grief responses to death or loss in a companion animal veterinary practice. In A. Katcher \& A. Beck (Eds.), New perspectives on our lives with companion animals (pp. 370-376). Philadelphia: University of Pennsylvania Press. 
Hill, R. P., Gaines, J., \& Wilson, R. M. (2008). Consumer behavior, extended-self, and sacred consumption: An alternative perspective from our animal companions. Journal of Business Research, 61(5), 553-562. http://dx.doi.org/10.1016/j.jbusres.2006.11.009

Hirschman, E. C. (1994). Consumers and their animal companions. Journal of Consumer Research, 20, 616-632. http://dx.doi.org/10.1086/209374

Hirschman, E. C., \& LaBarbera, P. A. (1990). Dimensions of Possession Importance. Psychology and Marketing, 7(3), 215-33. http://dx.doi.org/10.1002/mar.4220070306

Hoonakker, P., \& Carayon, P. (2009). Questionnaire Survey Nonresponse: A Comparison of Postal Mail and Internet Surveys. International Journal of Human-Computer Interaction, 25(5), 348-373. http://dx.doi.org/10.1080/10447310902864951

Jyrinki, H. (2012). Pet-related consumption as a consumer identity constructor. International Journal of Consumer Studies, 36(1), 114-120. http://dx.doi.org/10.1111/j.1470-6431.2011.00995.x

Jyrinki, H., \& Leipämaa-Leskinen, H. (2006). Pets as extended self in the context of pet food consumption. European Advances in Consumer Research, 7, 543-549.

Kara, A., Spillan J. E., \& DeShields, Jr. O. W. (2004). An empirical investigation of the link between market orientation and business performance in non profit service providers. Journal of Marketing Theory and Practice, 12(2), 59-72.

Leech, N. L., Barett, K. C., \& Morgan, G. A. (2008). SPSS for Intermediate Statistics: Use and Interpretation (3rd ed.). New York: Taylor and Francis Group, LLC.

Lefebvre, R. C. (2011). An integrative model for social marketing. Journal of Social Marketing, 1(1), 54-72. http://dx.doi.org/10.1108/20426761111104437

Leonard, H. A., \& Scammon, D. L. (2007). No Pet Left Behind: Accommodating Pets in Emergency Planning. Journal of Public Policy \& Marketing, 26(1), 49-53. http://dx.doi.org/10.1509/jppm.26.1.49

Levinson, B. M. (1969). Pet-oriented Child Psychology. Springfield, IL: Charles C. Thomas.

McCulloch, M. J. (1983). Animal-facilitated Therapy: Overview and Future Direction. In A. Katcher \& A. M. Beck (Eds.), New Perspectives in Our Lives with Companion Animals (pp. 410-426). Philadelphia: University of Pennsylvania Press.

Merriam-Webster.com. (2012). Retrieved July 11, 2012, from http://www.merriam-webster.com

Ridgway, N. M., Kukar-Kinney, M., Monroe, K. B., \& Chamberlin, E. (2008). Does excessive buying for self relate to spending on pets? Journal of Business Research, 61(5), 392-396. http://dx.doi.org/10.1016/j.jbusres.2007.07.002

Sanders, C. R. (1990). The Animal 'Other': Self-Definition, Social Identity and Companion Animals. In M.E. Goldberg et al. (Eds.), Advances in Consumer Research (vol. 17, pp. 662-668). Provo, UT: Association for Consumer Research.

Sanders, C. R. (1995). Killing with kindness: Veterinary euthanasia and the social construction of personhood. Sociological Forum, 10(2), 195-214. http://dx.doi.org/10.1007/BF02095958

Savishinsky, J. S. (1986). Pet ideas: the domestication of animals, human behavior and human emotions. In A. H. Katcher \& A. M. Beck (Eds.), New Perspectives in Our lives with Companion Animal (pp. 112-131). Philadelphia: University of Pennsylvania Press.

Serpell, J. (1986). In the Company of Animals. New York: Basic Blackwell.

Stephen, C., \& Brian, K. (2009). Pet Overpopulation: An Economic Analysis. Working Papers, Cornell University: Center for Analytic Economics.

Stephens, D. L., \& Hill, P. (1996). The Dispossession of Animal Companions: A Humanistic and Consumption Perspective. Society and Animals, 4(2), 189-210. http://dx.doi.org/10.1163/156853096X00151

Tuan, Y. (1984). Dominance and affection: The Making of Pets. New Haven, NY: Yale University Press.

Voith, V. L. (1981). Attachment between People and their Pets: Behavior Problems of Pets that Arise From the Relationship between Pets and People. In B. Fogle (Ed.), Interrelationships between People and Animals (pp. 271-294). Springfield, Illinois, IL: Charles C. Thomas.

Wacquant, L. J. D. (1992). Toward a Social Praxeology: The Structure and Logic of Bourdieu's Sociology. In P. 
Bourdieu \& L. J. D. Wacquant (Eds.), An Invitation to Reflexive Sociology (pp. 1-59). Chicago, IL: University of Chicago Press.

Wallendorf, M., \& Arnould, E. J. (1991). We Gather Together: Consumption Rituals of Thanksgiving Day. Journal of Consumer Research, 18, 13-31. http://dx.doi.org/10.1086/209237

Working Party, Council for Science and Society. (1988). Companion Animals in Society. Oxford, UK: Oxford University Press.

Zikmund, W., Babin, B., Carr, J., \& Griffin, M. (2010). Business Research Methods (8th ed.). Mason, OH: South-Western, Cengage Learning.

\section{Note}

Note 1 . Totals on tables may not add to 184 due to item non-response.

\section{Copyrights}

Copyright for this article is retained by the author(s), with first publication rights granted to the journal.

This is an open-access article distributed under the terms and conditions of the Creative Commons Attribution license (http://creativecommons.org/licenses/by/3.0/). 